\title{
Measuring changes in attitude, practice and knowledge of undergraduate nursing students after receiving an educational intervention in ethical comportment in critical care nursing
}

\author{
Hayam I. Asfour ${ }^{* 1,2}$, Fatma R. Ahmed ${ }^{1}$, Ghada E. Abd El Halim ${ }^{1}$ \\ ${ }^{1}$ Faculty of Nursing, Alexandria University, Alexandria, Egypt \\ ${ }^{2}$ Faculty of Nursing, Umm Al-Qura University, Mecca, Saudi Arabia
}

Received: August 25, 2015

DOI: $10.5430 /$ jnep.v6n5p49
Accepted: December 30, $2015 \quad$ Online Published: January 10, 2016

URL: http://dx.doi.org/10.5430/jnep.v6n5p49

\begin{abstract}
Objective: Critical care nurses face some of the most daunting ethical challenges in clinical practice. Nurses who work in intensive care and emergency rooms, and other highly specialized settings must have the ability to recognize the various ethical issues they face in the care of patients daily and to be prepared to address them in collaboration with patients, families, colleagues and administrators. Ethical comportment skills are similar to clinical skills, in which they can be learned and can be improved over time through using of several strategies and appropriate role modeling. The aim of the work was to measure changes in attitude, practice and knowledge of undergraduate nursing students after receiving an educational intervention in ethical comportment in critical care nursing.

Methods: The study design was a quasi-experimental research design. Setting: this study was conducted at Alexandria University, Faculty of Nursing, at Critical Care \& Emergency Nursing Department. Subjects of this study included 70 nursing students who completed the study. The tool of this study is "ethical comportment in critical care nursing students' assessment tool". It is used to assess students' attitude, knowledge and practice regarding ethical comportment.

Results: The levels of students' attitude, knowledge and practice towards items of ethical comportment increased after receiving an educational intervention in ethical comportment and the differences between attitude, knowledge and practice of student nurses towards items of ethical comportment pre and post the educational intervention were statistically significant.

Conclusions: From the findings of the current study it can be concluded that performing an educational intervention in ethical comportment can help in developing ethical comportment skills in critical care nursing students. Recommendation: nurses training should begin in the undergraduate level and must focus on the development and promotion of attitudes from which and acts by which care is provided.
\end{abstract}

Key Words: Ethical comportment, Ethical skills, Critical care, Nursing students

\section{INTRODUCTION}

Nowadays, many changes have occurred in society and health care such as: the commercialization of the health care system, the information technology revolution, the advancement of women's rights, extreme nurse shortages, the changes in managed care, the growing health care disparities, the systematic

\footnotetext{
*Correspondence: Hayam I. Asfour; Email: drhayamibrahim@ outlook.sa; Address: Department of Critical Care and Emergency Nursing, Faculty of Nursing, Alexandria University, Alexandria, Egypt.
} 
focus on improving patient safety, and more. In addition, there has been growing community concern regarding the ethical conduct of healthcare professionals. This is often reflected as complaints about poor ethical conduct and an increasing use of litigation against healthcare professionals. Nursing code of ethics has been included in the health professionals' training curriculum in many countries, and there has been a growth in the ethicists and ethical committees' number. Even though, complaints against healthcare professionals appear to proliferate. This may be a reflection of both an increased public awareness as well as the inappropriate practices by the healthcare professionals. ${ }^{[1-3]}$

For these reasons, the Carnegie study concluded that nurses are currently underprepared for the complex field of professional practice to face the changes in the health care system; therefore, the Carnegie study recommended sweeping changes in the pedagogies and curricular structures of nursing education. The formation of nurses' nursing identity, skilled know-how, knowledge use, character and improving the teaching of ethical comportment are key components of nursing power. Nurses' actions, behaviors, and comportment contribute to/or diminish the collective power that the profession of nursing holds in society, within a given organization, and in practice. ${ }^{[2,3]}$

Comportment is defined as "a dignified manner or conduct". Professional comportment is critical in determining nurses' effectiveness in communicating, relating and collaborating with colleagues and members of the health care team. In the absence of professional comportment, nurse aggression, a culture of incivility, and compromised patient safety will emerge. Individual accountability and self-regulation are sequels to professional comportment. The personal assimilation of professional comportment promotes harmony, mutual respect, collaboration and commitment. The patients, healthcare team and nurses are the beneficiaries of a nurse who demonstrates professional comportment. ${ }^{[2-6]}$

There are six ethical themes about ethical comportment of nurses which are: meeting the patient as a person, preserving the dignity and personhood of patients, know how to respond to substandard practice, patient advocacy, students and faculty engaged seriously in learning to do "good" nursing practice and learning how to be present with the patient and family suffering. These ethical themes are perceived by nurses and are derived from the nursing code of ethics. ${ }^{[2-6]}$

Ethical comportment helps nurses justify what is or is not correct and appropriate professional conduct. It also promotes the rights of health services users and the principles of bioethics, which are crucial elements in humanized care. Insufficient exposure to and/or inadequate knowledge, attitude and practical skills of ethical comportment in nursing education programs has been known as contributing to a lack of commitment to ethics as a professional priority and poor socialization of nurses to their ethical responsibilities. ${ }^{[7-10]}$

Acute and critical care nurses encounter ethical "quandaries" routinely such as providing futile care. Ethically important occurrences may go unrecognized. The primary concern of nurses must be providing good care. Nurses training must focus on the development and promotion of attitudes from which and acts by which care is provided as nursing care targets precisely the essential integration of skills knowledge and caring. Ethical skills are similar to clinical skills, as they can be experientially learned and can be improved over time using several strategies and appropriate role modeling. ${ }^{[7-10]}$

To educate ethic for nurses, many approaches can be used. One approach is to introduce nurses to the principles of performing the right action as codes of ethics for nurses: confidentiality, informed consent, and non-discrimination. Another approach places greater emphasis on the caring attitude as a starting point for good nursing care and consists of a virtue ethics approach to ethics education and this approach was proposed by Van Hooft. ${ }^{[7]}$ Teaching nurses ethic is not just teaching how to avoid litigation or conformity to codes; it is essential to empower nurses to act in stressful or difficult situations, especially when the objective guidelines are not available; this as viewed by Van Hooft in his approach. ${ }^{[7]}$

In a study conducted to examine nurses' attitudes in relation to health care ethics, nurses considered ethical problems important in daily clinical practice, but at the same time, nurses considered themselves not sufficiently trained to resolve those situ-ations. ${ }^{[11]}$ Another study highlighted the gap in the knowledge and the practical aspects of health care ethics among nurses. ${ }^{[12]}$ Although ethics of nurses is critical to the quality of nursing care, little has been documented about nurses' knowledge in ethics, their formal and in-service ethics training in the developing countries. ${ }^{[10-13]}$ To date, there is limited documentation on the current knowledge and competencies in ethical comportment among practicing nurses in Egypt. Therefore, this study aimed to measure changes in attitude, practice and knowledge of undergraduate nursing students after receiving an educational intervention in ethical comportment in critical care nursing.

The research hypothesis was: students will score higher on attitudes, practice and knowledge after receiving an educational intervention in ethical comportment in critical care nursing. 


\section{SUBJECT AND METHOD}

\subsection{Study design}

Quasi-experimental research design with pre-post assessment was used in the study that is appropriate for the nature of current research hypothesis and frequently used in nursing researches.

\subsection{Setting}

The present study was conducted in Critical Care \& Emergency Nursing Department Faculty of Nursing, Alexandria University, Egypt and in the general critical care unit in the main University Hospital in Alexandria, Egypt.

\subsection{Subject}

The subjects of this study included 180 nursing students enrolled in critical care nursing (II) course in the 6th semester during the academic year (2012-2013). 50 students refused to participate in the study and 60 students did not complete the study. Therefore, the subjects of this study included 70 nursing students who completed the study. All students were in the age group ranging from 20-23 years old. 50 students were females and 20 were males and studied the same courses, which contain few topics regarding ethics, but Ethics in nursing as a separate course will be studied in the 7 th semester.

The data collection instrument was "Ethical comportment in critical care nursing students' assessment tool". The researchers developed this tool after reviewing the related literatures. ${ }^{[1-6,11-15]}$ It is used to assess students' attitude, knowledge and practice regarding ethical comportment. It includes three parts:

\section{Part I Ethical attitudes of critical care nursing students}

This part was used to assess students' ethical attitudes pre and post educational intervention in ethical comportment. The attitude questionnaire consists of 30 items related to main ethical comportment skills in nursing care such as: meeting the patient as a person, preserving the dignity of patients, responding to substandard practice, patient advocacy, learning how to be present with patient and family suffering and engaging in learning to do "good" nursing practice.

Examples of items: The nurse should respect the patient as a person, critically ill patients shouldn't make choices regarding their treatments, critically ill patients have not the right to determine what will be done with their own person, nurses should actively promote the collaborative multi-disciplinary planning required to ensure the availability of quality health services to all patients who have needs for health care, the nurse sometimes cannot safeguard critically ill patient's right to privacy, the nurse should advocates for an auditory privacy

Published by Sciedu Press for discussions of patients' conditions, the nurse must should take appropriate action regarding any instances of incompetent, or impaired practice by any member of the health care team, reporting unethical, or impaired practices may present substantial risks to the nurse, etc.

Scoring system: The tool has a 5 point Likert scale. This was used to represent students' attitudes scored on 5 point scale, i.e., 1 (Strongly Disagree), 2 (Disagree), 3 (Uncertain), 4 (Agree) to 5 (Strongly Agree). Fifteen of the items were worded positively, and fifteen were worded negatively. The scores of each area of attitude were added and converted into a percent score. Thus, possible score range was 30 to 150. A higher score indicates a more positive ethical attitude. Favorable attitude $\geq 50 \%$ of the total score and unfavorable attitude $\leq 50 \%$ of the total score.

\section{Part II Ethical knowledge of critical care nursing students}

This part of the tool includes knowledge questions to assess student's ethical knowledge pre and post the educational intervention in ethical comportment. It includes 30 multiplechoice questions related to main ethical comportment skills in nursing care such as: meeting the patient as a person, preserving the dignity of patients, responding to substandard practice, patient advocacy, learning how to be present with patient and family suffering and engaging in learning to do "good" nursing practice.

Example of questions: A nurse offers pain medication to a patient is an example of which ethical term? a-autonomy b-nonmaleficence c-beneficience d-fidelity. Another example; nurses agree to be advocates for their patients; practice of advocacy calls for the nurse to: a-seek out the nursing supervisor in conflicting situations, b-work to understand the law as it applies to the client's clinical condition, c-assess the patient's point of view and prepare to articulate this point of view, d-document all clinical changes in the medical record in a timely manner.

Scoring system: For each items had two levels of responses as the correct answer for any item was given score of one and incorrect answer or do not know given zero. Total responses for all items was 30 score equal to $100 \%$ related to students responses. The scores of each area of knowledge were added and converted into a percent score. The possible score range was 0 to 30. A high score indicates better knowledge. Good knowledge $\geq 75 \%$ of total score and poor knowledge $\leq 75 \%$ of the total score.

\section{Part III Ethical practical skills of critical care nursing stu- dents}

The researchers constructed this part from various literatures related to ethical practice. It was used to assess stu- 
dents' ethical practical skills regarding ethical comportment through asking questions about how to apply their ethical skills in caring for critically ill patients. It consists of eight multiple-choice practical questions reflecting the same items of knowledge and attitude.

Example of practical questions: To respect a patient's personal space, the nurse: (a) avoids the use of touch, (b) explains nursing care and procedures, (c) keeps the curtains pulled around the clients bed, (d) stands 8 feet away from the bed, if possible. Another example; the nurse is caring for a seriously ill patient, surgery has been proposed for the patient, but the chances of success are unclear, in helping the patients' family resolve this ethical conflict, the nurse knows that the first step is (a) exploring reasonable courses of action, (b) collecting all available information about the situation, (c) clarifying values related to the cause of the dilemma, (d) identifying people who can solve the difficulty.

Scoring system: Each items had two levels of responses: proper practice scored one while improper practice scored zero. Total responses of all items was 8 scores and equal to $100 \%$ related to students responses. The scores of each area of knowledge were added and converted into a percent score. The possible score range was 0 to 8 . A high score indicates proper practice. Proper practice was considered when student score is more than or equal $75 \%$ of total knowledge aspect of practice questions while improper practice was considered when the score is less than $75 \%$ of total knowledge aspect of practice questions.

In addition to the data, regarding demographic factors and students' characteristics, including age, sex.

\subsection{Tools validity and reliability}

The current study tool were submitted to five academic nursing experts in the critical care \& emergency nursing and the nursing education fields to test the face and content validity of the tool, necessary modifications were carried out according to the academic nursing experts' judgment on clarity of sentences and the appropriateness of the content. Tool reliability was tested using internal consistency methods (Alpha Cronbach test). Its result was 0.858 which indicates an accepted reliability of the tools.

\subsection{Pilot study}

A pilot study was conducted on $14(20 \%)$ students. It was selected from the previously mentioned study setting according to inclusion criteria to assess the current study tools for its clarity, validity, applicability and the time required to fill the tool. Necessary modifications of the tool were done according to pilot results to reach the finalized form. The subjects who included in the pilot study were excluded from the total study sample.

\subsection{Procedure}

The study was achieved through three phases namely; assessment, implementation, and evaluation. This study started from the beginning of February to the end of June 2013. The researchers trained and monitored the students for 4 hours a day once a week. The researchers began with introducing themselves and providing clear explanation about the nature, aim and purpose of the current study to the students. Each student was informed that sharing in this study is voluntary. Oral approval of students to share in this study was achieved.

\subsubsection{Assessment phase}

The purpose of this phase was to collect data regarding students' ethical comportment and identify students' ethical skills needs. Data related to demographic factors and students' characteristics, including age, sex were collected. A pretest was done to all students on ethical knowledge, attitude and practice using the tool to evaluate their ethical comportment skills; this was conducted in the first week of the semester.

\subsubsection{Implementation phase}

After orienting the students about the aim of the study, students were informed (oral and written). The intervention was designed based on review of relevant literature and students' needs identified in the pre-test in order to provide competent nursing care. The theoretical part emphasized on improving students' ethical comportment skills. In the second and third week of the semester, ten teaching sessions were conducted by the researchers to explain the application of the ethics in clinical practice in critical care nursing and how to use nursing code of ethics in their clinical practice. Students were classified into 5 groups each group consisted of 14 students and each group of students had 2 teaching sessions. Questions were encouraged throughout this process and were given the feedback regarding what has been done.

Students were given a handout for the ethical comportment and code of ethics in critical care nursing and its applications in clinical practice which include explanation of several items as the nurse must perform the following: treating people as individuals, respecting people's confidentiality, collaborating with other people to provide optimal care, gaining informed written consent, sharing information with colleagues, working as part of a team effectively, managing risk, and providing a high standard of practice and care at all times and settings, know how to respond to substandard practice, patient advocacy, students and faculty engaged seriously in learning to do "good" nursing practice and learning how to be present with patient and family suffering. using the best available 
evidences, keeping knowledge and skills up to date, keeping accurate and clear records, acting with integrity, dealing with problems and upholding the nursing profession reputation.

In addition, the educational intervention included some student learning activities such as students followed actual client throughout their clinical training in the hospital and documented the various points at which an action was taken, students maintained a self-reflection journal in which they recorded examples of desirable and undesirable professional behaviors they shown during a clinical day. After that, students discussed how they as nurses could have changed an undesirable behavior to a desirable behavior. Each student had the opportunity to discuss at least one example of any ethical issue they witnessed on the clinical unit, and use debriefing techniques to evaluate the situation.

During the semester for nine weeks (from the 4th to the 12th week), students were continuously assessed and monitored (from the researchers as their supervisors in the clinical training) for their ethical comportment skills and their performance with patients, patients' families, colleagues and the other health team members. The researchers discussed with students the nursing care of their patients considering the ethical aspects of care. The researchers trained and monitored the students for 4 hours a day once a week.

\subsubsection{Evaluation phase}

Two evaluation were done for students, the first one was at the beginning of the study (in the first week of the semester) as a baseline data. Second evaluation was conducted in the week thirteen, students' ethical comportment skills were evaluated after the educational intervention, as post-test for knowledge, attitude and practice. The same assessment tool was used during the two evaluations.

\subsection{Administrative design and ethical considerations}

The study conducted over a period of 5 months from February to the end of June 2013. An official letter clarifying the purpose and setting of the study was obtained from the ethical committee and the head of Critical Care \& Emergency Nursing Department, Nursing Faculty-University of Alexandria-Egypt, and from the hospital authority to conduct the study. Each student was informed about the significant and aim of the study and then an informed written consent was obtained from each student before he/she participates in the study. All students were informed that their participation is voluntary. The anonymity, the confidentiality, and the right to refuse to participate and/or withdraw from the study were assured. Confidentiality was assured and maintained with students, self-selecting an identifying code known only to them. Thus, the data collection were completed anony- mously. Students were made aware that their course grade was in no way influenced by their participation in the study.

\subsection{Statistical analysis}

Statistical Package for Social Sciences (SPSS) version 17.0 was used for quantitative data analysis. Data were presented using descriptive statistics in the form of frequencies and percentages for qualitative variables and means and standard deviations and medians for quantitative variables. Cronbach alpha coefficient was calculated to assess the reliability of the developed tool through their internal consistency. Quantitative data were compared using independent simples $T$-Test. A significant $p$-value was considered when $p$ less than .05 .

\section{Results}

Table 1 shows the distribution of student nurses' attitude according to degree of agreement towards items of ethical comportment pre and post the educational intervention. Regarding items of meeting the patient as a person, more than half of students agreed and strongly agreed in the pretest, which improved to be all students agreed and strongly agreed in the posttest. Fifty percent of students were uncertain and $38.57 \%$ disagreed to preserve the dignity of critically ill patients in the pretest and increased in the posttest to be more than $92 \%$ of students agreed and strongly agreed with it. Forty students agreed and strongly agreed with items of responding to substandard practice in the pretest and increased in the posttest to be fifty students. Thirty students agreed and strongly agreed with items of patient advocacy in the pretest and increased in the posttest to be fifty students. Fifty students strongly disagreed (24.28\%), disagreed (14.28\%) and uncertain $(32.85 \%)$ with items of engaging in learning to do "good" nursing practice in the pretest and improved to be fifty students agreed $(35.71 \%)$ and strongly agreed $(35.71 \%)$ with these items in the posttest. As for items of learning how to be present with patient and family suffering, only $20(28.57 \%)$ were uncertain and $33(47.14 \%)$ agreed and $17(24.28 \%)$ strongly agreed with these items in the pretest compared with $30(42.85 \%)$ agreed and $40(57.14 \%)$ strongly agreed in the posttest.

Table 2 shows student nurses' knowledge towards items of ethical comportment pre and post the educational intervention. More than a third $(38.57 \%)$ of students responded correctly on questions regarding meeting the patient as a person in the pretest and increased to $88.57 \%$ in the posttest. Fifty students responded correctly on questions regarding preserving the dignity of patients in the pretest and improved to be $92.86 \%$ in the posttest. As for responding to substandard practice; only five students answered questions correctly in the pretest compared with fifty students in the posttest. 
Forty students answered questions regarding patient advocacy in the pretest and increased to be 64 students in the posttest. Twenty students responded correctly to questions about engaging in learning to do "good" nursing practice in the pretest and increased to be 51 students in the posttest.
As for questions about learning how to be present with patient and family suffering, 25 students answered questions correctly in the pretest and increased to 66 students in the posttest.

Table 1. Distribution of student nurses' attitude according to degree of agreement towards items of ethical comportment pre and post the educational intervention. (Total number $=70)$

\begin{tabular}{|c|c|c|c|c|c|c|c|c|c|c|c|}
\hline \multirow[t]{2}{*}{ Attitude of students } & & \multicolumn{2}{|c|}{$\begin{array}{l}\text { Strongly } \\
\text { Disagree }\end{array}$} & \multicolumn{2}{|c|}{ Disagree } & \multicolumn{2}{|c|}{ Uncertain } & \multicolumn{2}{|c|}{ Agree } & \multicolumn{2}{|c|}{$\begin{array}{l}\text { Strongly } \\
\text { Agree }\end{array}$} \\
\hline & & $\mathbf{N}$ & $\%$ & $\mathbf{N}$ & $\%$ & $\mathbf{N}$ & $\%$ & $\mathbf{N}$ & $\%$ & $\mathbf{N}$ & $\%$ \\
\hline \multirow{2}{*}{ Meeting the patient as a person } & Pre & 5 & 7.14 & 20 & 28.57 & 25 & 35.71 & 27 & 38.57 & 26 & 37.14 \\
\hline & Post & 0 & 0 & 0 & 0 & 0 & 0 & 40 & 57.14 & 30 & 42.85 \\
\hline \multirow{2}{*}{$\begin{array}{l}\text { Preserving the dignity of } \\
\text { patients }\end{array}$} & Pre & 0 & 0 & 27 & 38.57 & 35 & 50 & 8 & 11.42 & 0 & 0 \\
\hline & Post & 0 & 0 & 0 & 0 & 5 & 7.14 & 30 & 42.85 & 35 & 50 \\
\hline \multirow{2}{*}{$\begin{array}{l}\text { Responding to substandard } \\
\text { practice }\end{array}$} & Pre & 5 & 7.14 & 18 & 25.71 & 17 & 24.28 & 30 & 42.85 & 10 & 14.28 \\
\hline & Post & 0 & 0 & 10 & 14.28 & 10 & 14.28 & 20 & 28.57 & 30 & 42.85 \\
\hline \multirow{2}{*}{ Patient advocacy } & Pre & 0 & 0 & 22 & 31.42 & 18 & 25.71 & 20 & 28.57 & 10 & 14.28 \\
\hline & Post & 0 & 0 & 10 & 14.28 & 8 & 11.42 & 32 & 45.71 & 20 & 28.57 \\
\hline \multirow{2}{*}{$\begin{array}{l}\text { Engaging in learning to do } \\
\text { "good" nursing practice }\end{array}$} & Pre & 17 & 24.28 & 10 & 14.28 & 23 & 32.85 & 15 & 21.42 & 5 & 7.14 \\
\hline & Post & 8 & 11.42 & 7 & 10 & 5 & 7.14 & 25 & 35.71 & 25 & 35.71 \\
\hline \multirow{2}{*}{$\begin{array}{l}\text { Learning how to be present with } \\
\text { patient and family suffering }\end{array}$} & Pre & 0 & 0 & 0 & 0 & 20 & 28.57 & 33 & 47.14 & 17 & 24.28 \\
\hline & Post & 0 & 0 & 0 & 0 & 0 & 0 & 30 & 42.85 & 40 & 57.14 \\
\hline
\end{tabular}

Table 2. Distribution of student nurses' according to their knowledge towards items of ethical comportment pre and post the educational intervention

\begin{tabular}{|c|c|c|c|c|c|}
\hline \multirow{3}{*}{ Knowledge items of students } & & \multicolumn{4}{|c|}{ Total $=70$} \\
\hline & & \multicolumn{2}{|c|}{ Incorrect } & \multicolumn{2}{|c|}{ Correct } \\
\hline & & $\mathbf{N}$ & $\%$ & $\mathbf{N}$ & $\%$ \\
\hline \multirow{2}{*}{ Meeting the patient as a person } & Pre & 43 & 61.43 & 27 & 38.57 \\
\hline & Post & 8 & 11.43 & 62 & 88.57 \\
\hline \multirow{2}{*}{ Preserving the dignity of patients } & Pre & 35 & 50 & 35 & 50 \\
\hline & Post & 5 & 7.14 & 65 & 92.86 \\
\hline \multirow{2}{*}{ Responding to substandard practice } & Pre & 65 & 92.86 & 5 & 7.14 \\
\hline & Post & 20 & 28.57 & 50 & 71.43 \\
\hline \multirow{2}{*}{ Patient advocacy } & Pre & 30 & 42.85 & 40 & 57.14 \\
\hline & Post & 6 & 8.57 & 64 & 91.43 \\
\hline \multirow{2}{*}{ Engaging in learning to do "good" nursing practice } & Pre & 50 & 71.43 & 20 & 28.57 \\
\hline & Post & 19 & 27.14 & 51 & 72.86 \\
\hline \multirow{2}{*}{ Learning how to be present with patient and family suffering } & Pre & 45 & 64.29 & 25 & 35.71 \\
\hline & Post & 4 & 5.71 & 66 & 94.29 \\
\hline
\end{tabular}

Table 3 shows knowledge aspect of practice of student nurses towards items of ethical comportment pre and post the educational intervention. Nearly fifty students $(68.57 \%)$ in the pretest responded correctly on practical questions regarding meeting the patient as a person and increased to 67
(95.7\%) in the posttest. Nearly half of students responded correctly on practical questions regarding preserving the dignity of patients in the pretest and improved to be $91.4 \%$ in the posttest. As for performing actions towards substandard practice, thirty students were able to take appropriate actions 
in the pretest and doubled to reach 61 students in the posttest. do "good" nursing practice in the pretest and increased to be Forty-three students answered practical questions correctly regarding patient advocacy in the pretest and increased to be 53 students in the posttest. Twenty-six students responded 58 students in the posttest. As for practice of learning how to be present with patient and family suffering, 32 students correctly to practical questions about engaging in learning to were able to care for patients and family suffering in the pretest and increased to 60 students in the posttest.

Table 3. Practice of student nurses towards items of ethical comportment pre and post the educational intervention

\begin{tabular}{|c|c|c|c|c|c|}
\hline \multirow{3}{*}{ Practice items of students } & & \multicolumn{4}{|c|}{ Total $N=70$} \\
\hline & & \multicolumn{2}{|c|}{ Incorrect } & \multicolumn{2}{|c|}{ Correct } \\
\hline & & $\mathbf{N}$ & $\%$ & $\mathbf{N}$ & $\%$ \\
\hline \multirow{2}{*}{ Meeting the patient as a person } & Pre & 22 & 31.42 & 48 & 68.57 \\
\hline & Post & 3 & 4.3 & 67 & 95.7 \\
\hline \multirow{2}{*}{ Preserving the dignity of patients } & Pre & 36 & 51.43 & 34 & 48.57 \\
\hline & Post & 6 & 8.6 & 64 & 91.4 \\
\hline \multirow{2}{*}{ Responding to substandard practice } & Pre & 40 & 57.14 & 30 & 42.86 \\
\hline & Post & 9 & 12.9 & 61 & 87.1 \\
\hline \multirow{2}{*}{ Patient advocacy } & Pre & 27 & 38.57 & 43 & 61.43 \\
\hline & Post & 17 & 24.3 & 53 & 75.7 \\
\hline \multirow{2}{*}{ Engaging in learning to do "good" nursing practice } & Pre & 44 & 62.86 & 26 & 37.14 \\
\hline & Post & 12 & 17.1 & 58 & 82.9 \\
\hline \multirow{2}{*}{ Learning how to be present with patient and family suffering } & Pre & 38 & 54.29 & 32 & 45.71 \\
\hline & Post & 10 & 14.3 & 60 & 85.7 \\
\hline
\end{tabular}

Table 4 shows the comparison between attitude, knowledge and practice of student nurses towards items of ethical comportment pre and post the educational intervention. Students' attitude towards items of ethical was improved after the educational intervention as 60 students had unfavorable attitude in before the educational intervention and changed to be 68 students who had favorable attitude and this difference was statistically significant $(p=.000)$. Similarly, there were changes in the level of knowledge of student nurses towards items of ethical comportment pre and post the educational intervention. As 58 students had poor knowledge before the educational intervention and improved to be 63 students their knowledge were good and the difference was statistically significant $(p=.000)$. only eight students had good practical skills before the educational intervention and the level of students performance was increased after the educational intervention to be 62 for students who had good practical skills and the difference was statistically significant $(p=.000)$.

Table 4. Comparison between attitude, knowledge and practice of student nurses towards items of ethical comportment pre and post the educational intervention

\begin{tabular}{|c|c|c|c|c|c|c|}
\hline \multirow{3}{*}{ Items } & & \multicolumn{4}{|c|}{ Total N = 70} & \multirow{3}{*}{$p$} \\
\hline & & \multicolumn{2}{|c|}{ Pre } & \multicolumn{2}{|c|}{ Post } & \\
\hline & & $\mathbf{N}$ & $\%$ & $\mathbf{N}$ & $\%$ & \\
\hline \multirow{3}{*}{ Attitudes } & Favorable & 2 & 2.86 & 68 & 97.14 & \multirow{3}{*}{$.000^{*}$} \\
\hline & Unfavorable & 60 & 85.72 & 10 & 14.28 & \\
\hline & $\mathrm{M} \pm \mathrm{SD}$ & \multicolumn{2}{|c|}{$1.02 \pm .167$} & \multicolumn{2}{|c|}{$1.85 \pm .352$} & \\
\hline \multirow{3}{*}{ Knowledge } & Good & 7 & 10 & 63 & 90 & \multirow{3}{*}{$.000^{*}$} \\
\hline & Poor & 58 & 82.9 & 12 & 17.1 & \\
\hline & $\mathrm{M} \pm \mathrm{SD}$ & \multicolumn{2}{|c|}{$1.10 \pm .302$} & \multicolumn{2}{|c|}{$1.82 \pm .379$} & \\
\hline \multirow{3}{*}{ Knowledge aspect of practice } & Good & 8 & 11.43 & 62 & 88.57 & \multirow{3}{*}{$.000^{*}$} \\
\hline & Poor & 62 & 88.57 & 8 & 11.43 & \\
\hline & $\mathrm{M} \pm \mathrm{SD}$ & \multicolumn{2}{|c|}{$1.11 \pm .320$} & \multicolumn{2}{|c|}{$1.82 \pm .379$} & \\
\hline
\end{tabular}

*Significant at $5 \%$ level 


\section{Discussion}

Ethics is a vital part of the nursing profession. Code of Ethics reminds all nurses of their responsibilities towards patients and communities, namely to prevent illness, preserve life, alleviate suffering protect, promote and restore health Therefore, nurses' responsibilities should be carried out with the required respect for human rights such as: the right to life, choice and dignity without consideration of age, color, disability or illness, gender, or social status. ${ }^{[16-19]}$ Ethical comportment reflects code of ethics principles that serve as messages by nurses that they will always provide due care to the healthcare consumers to the best of their abilities. ${ }^{[18-22]}$ It was reported by many critical care nurses that they have received a little ethical preparation in their basic nursing education to deal with the sensitive issues in their clinical settings. Nurse educators who are responsible for designing and teaching undergraduate critical care nursing courses are obligated to consider and address the ethical comportment and ethical skills as a part of the nursing curriculum because the new graduate nurses often choose to specialize in critical care nursing..$^{[7,8,10]}$

Students' understanding of ethics can be increased by allowing students to participate in the clinical analysis of patients' conditions and nurse educators teaching critical care courses can teach and allow students to apply this in their clinical training. ${ }^{[8]}$ The Carnegie Foundation National study of nursing education recommended four of six key shifts in teaching and learning in nursing education which were focused by Benner, Sutphen and Day. ${ }^{[2]}$ The researchers mentioned that, it is important to help nurse educators think about and approach their teaching in new ways, therefore; these shifts were required to strengthen education for formation and ethical comportment in nursing. These shifts focused on the integration of the three apprenticeships, which are cognitive knowledge, practical know-how, and ethical comportment and formation. In addition to transforming teaching from clinical and classroom teaching separately to the integration of both classroom and clinical teaching. ${ }^{[2]}$

It is important to provide the nursing students the opportunity to discuss and debate all expected ethical issues in their teaching and train them how to make an analysis for the clinical ethical issues under the guidance of their informed instructors. This training will offer a valuable experience for students to handle the ethical issues they face during their nursing practice. ${ }^{[23-25]}$ Therefore, the aim of this study was to measure changes in attitude, practice and knowledge of undergraduate nursing students after receiving an educational intervention in ethical comportment in critical care nursing.

In the current study, there was a significant difference be- tween the students' knowledge, attitude and practice of ethical comportment skills before and after the training. Students may consider studying ethic is a hard issue because of many terminologies and no practical training on it but in the current study, students were educated and trained to analyze the patients' conditions and interpret the reactions and feelings of patients and their families. Consequently, the results of the current study may be due to the practical training of ethical comportment, allowing students to discuss patients' problems and analyze the issues of care from the ethical point of view, supervision and feedback given to students during their training.

The results of this study were in the line with many studies. ${ }^{[11-15]}$ A study was conducted by Osingada et al. ${ }^{[11]}$ to evaluate nurses' ethics knowledge and practice and to identify nurses' perceptions/attitudes towards continuing nurses' ethics education (CNEE). The questions in Osingada study assessed participants' knowledge of basic concepts in nursing ethics, nurses' ethical comportment and their application in nursing care. Overall, only $16 \%$ of nurses scored $\geq 50 \%$ in the ethics knowledge test, up to $93 \%$ of the participants agreed that it is important to receive CNEE, and 95.6\% agreed that CNEE is required to improve nurses' ethics knowledge and practice and they need training in nursing ethics. ${ }^{[1]}$

Also, in the study of Iglesias and Vallejo, ${ }^{[12]}$ the researchers focused on assessing the knowledge, and attitudes of nurses in relation to health care ethics. The researchers found that nurses are very concerned about situations that create ethical conflicts and do not feel sufficiently trained to handle the ethical issues in their clinical settings. Thus, the researchers concluded that; although the nurses have university-level education about bioethics, they require periodic continuing education in ethical comportment. Aliyu et al. ${ }^{[14]}$ study was designed to determine knowledge, attitude and practice of ethical comportment among nurses at the Federal Medical Centre, Bida. The main findings of this study were that nurses possess considerably good knowledge, practice and attitude of nursing ethics. Nurses identified several options as remedies to reduce the incidence of ethical issues in their practice area. These options include: periodic workshops, adherence to nursing code of ethics and ethical comportment. ${ }^{[14]}$

Gustafsson, Eriksson, Strandberg, and Norberg ${ }^{[25]}$ stated that lack of support and time to provide the needed patients' care and perceived inability to live up to expectations of oneself and those of peers and supervisors, were considered factors that decrease ethical comportment leading to decrease the quality of nursing care provided. ${ }^{[25]}$ 
Chopra et al. ${ }^{[13]}$ assessed the knowledge of, and attitudes to healthcare ethics among north Indian nurses and physicians. The findings of this study indicated gaps in the knowledge about the practical aspects of health care ethics among nurses and physicians, which they encounter in day-to-day practice in their workplace and recommended that practical education in ethics, could assist in bridging the gap in ethical approaches among different levels of healthcare staff. Similarly, in a study of Hariharan et al. ${ }^{[15]}$ the researchers found that physicians had a stronger opinion than nurses regarding the practice of ethical comportment such as adherence to patients' wishes, consent for procedures, confidentiality and treating non-compliant patients and the study recommended that practical education in ethical comportment, particularly in a multidisciplinary settings, could assist in bridging the gap in ethical approaches between physicians and nurses. ${ }^{[15]}$

In the current study, students were trained to view patients problems from all aspects as physical needs, psychological needs, etc. In addition, they were trained to analyze patients' problems from the ethic of caring. In this respect, Robichaux, and Parsons ${ }^{[26]}$ stated that: making a relationship with the patient involved, and putting themselves in the patient's position should be considered by critical care nurses. Undergraduate nurses are subject to personal motives and misunderstandings despite these affective responses. ${ }^{[26-28]}$

Protecting the rights of patients, maintaining autonomy and patients' privacy are more frequent ethical comportment issues that facing nurses in their practice as stated by Ulrich $e t$ $a l .{ }^{[29]}$ The researchers also found that these issues were the most stressful ethical issues encountered by nurses. ${ }^{[29]}$ Undergraduate students should have the necessary knowledge and skills to report, especially reporting illegal, incompetent or impaired practices. Adequate support and encouragement should be given for students to report in a professional way. Codes of ethics provide nurses with clear-cut ethical principles to direct their ethical comportment skills. Codes of ethics encourage reflection on nurses' practice as they help nurses to reflect ethically and enhance caring attitudes of nurses. ${ }^{[7,22,23,30]}$ In the same respect, Fry and Johnstone encourage using the codes of ethics in daily nursing practice. ${ }^{[31]}$ The researchers used a workbook contains essential background information on how to reflect ethically on nursing practice. ${ }^{[31]}$

It is important to include ethics in the education of nursing, as it is considered essential for the profession of nursing and for nursing practice. In the present study, students gained the ethical comportment skills, as there were statistical differences between students' levels of knowledge, attitude and practice before and after training on ethical comportment.
Grady et al. ${ }^{[32]}$ suggested the continuing ethical education helps improving and maintaining the ethical comportment skills, which support the results of the current study. Nurses' self-confidence in their ethical skills and their ability to provide high quality of care increase in Grady's ${ }^{[32]}$ study as reported by nurses and this is because of receiving such ethical comportment training. Wocial ${ }^{[33]}$ also, suggested moving beyond the debate on the ethical education content and provide ethical education continuously.

Even for new nurses, the researchers paid a great attention to educate them about ethics especially in the clinical practice. Jurchak and Pennington ${ }^{[34]}$ developed a program for the new critical care nurses to enhance their ethical comportment skills. There are three objectives in this program: First, it is to provide nurses with a safe space to talk about and discuss the ethical issues in critical care settings. Second, it is to introduce and apply an ethical framework for analysis of ethical issues. Third, it is to allow nurses to identify supportive resources in the institution. The new nurses evaluated this program initially and expressed their satisfaction by sharing the ethical problems and receiving constructive feedback and this evaluation was positive. ${ }^{[34]}$

The Clarian Health System used Unit-Based Ethics Conversations (UBEC) in ethic education. ${ }^{[35]}$ The importance of UBEC is being a program in which anyone can export and implement the education strategies. UBEC provides staff nurses with opportunities to develop confidence and ethical comportment skills in managing difficult ethical situations. The evaluation in UBEC is formal and ongoing. ${ }^{[35]}$

In the same line, $\mathrm{Hsu}^{[36]}$ performed a study aimed to encourage students to apply the ethical comportment principles in their clinical practice. Hsu used scenario-based learning (SBL) to train students as SBL focuses on the basis of ethics and personal and professional values related to ethics in clinical nursing. SBL primarily concerns with basic concepts of ethics and their application of ethical comportment skills. Hsu designed scenarios based on real clinical situations. Nursing students of this study taught useful lessons out of their experience and were able to cope with similar situations with enhanced knowledge and confidence. The findings of Hsu's study ${ }^{[36]}$ support the effectiveness of using case-based method in facilitating learning and enhancing student satisfaction with a learning experience. Another study on undergraduate student nurses were done by Engward ${ }^{[37]}$ to explore the students' situated experience of ethics using story discussion groups; the stories have conveyed aspects of clinical context that may not be observed. Engward had concluded that the stories and discussion on educating ethical comportment skills have been a powerful means in accessing 
students' understandings. ${ }^{[37]}$

The limitations of this study included the study design. The quasi-experimental design allowed for study subjects who were not randomly assigned. The subjects of this study included 180 nursing students and only 70 nursing students who completed the study. Generalizability of results is limited due to the small sample size. Shortage of similar studies carried out in Egypt, Arabic countries and in other parts of the world make the comparison and discussion difficult. Lack of a standard tool for nurses' attitude and practice and especially on students were the challenges of this study. Changes in someone's attitude are hard and need long time and continuity therefore, practical education of ethic in nursing should be applied from the first semester in nursing education until students 'graduation to make the desired improvement.

\section{Conclusion}

The primary concern of critical care nurses is to provide good care. Nursing care is based on the integration of knowledge and skills and caring; therefore, nurses' training should focus on development of ethical comportment skills needed to face the ethical issues in clinical practice. ${ }^{[10]}$ Having ethical comportment skills help nurses to provide care effectively of critically ill patients and their families. Presence of a system is essential for nurses to know how to face and respond ethi- cally to patients' problems in the real situations. This should begin with undergraduate student nurses. From the findings of the current study, it can be concluded that performing educational intervention in ethical comportment can help in developing ethical comportment skills in critical care nursing students.

\section{Recommendation}

Healthcare institutions should consider how the ethical problems that nurses encounter in their work, may affect their level of stress and their ability to do good for their patients. Therefore, it is recommended that the training of nurses should begin in the undergraduate level and should continuously focus on the development of caring attitudes from which care is provided. When teaching critical care courses, nurse educators can encourage students' participation in clinical analysis of case studies especially in clinical areas and thus increase students' understanding of ethical principles and dilemmas. Adherence of codes of ethics in clinical practice can enhance ethical comportment skills. The study can be conducted on a large sample of students and in different clinical settings.

\section{CONFLiCTS OF INTEREST Disclosure}

The authors declare that there is no conflict of interestc.

\section{REFERENCES}

[1] Lachman V. Applying the Ethics of Care to Your Nursing Practice. Med Surg Nursing. 2012; 21(2): 112-6. PMid:22667005

[2] Benner P, Sutphen M, Leonard-Kahn V, et al. Formation and Everyday Ethical Comportment. Am J Crit Care. 2008; 17: 473-6. PMid:18776004

[3] Jennings B, Baily M, Bottrell M, et al. Health Care Quality Improvement: Ethical and Regulatory Issues. Garrison, New York: The Hastings Center. 2007; 25-5. PMid:18019267

[4] Butts J. Ethics in professional Nursing Practice. Jones and Bartlett Publishers. 2008. Available from: http://www.jblearning.com /samples/.../48986_ch03_pass3.pdf

[5] Bostrom N, Roache R. Ethical Issues in Human Enhancement: in Jesper Ryberg ed. New Waves in Applied Ethics. 2007.

[6] American Heart Association. Part 2: Ethical Aspects of CPR and ECC. Circulation. 2000.

[7] Van Hooft S. Moral education for nursing decisions. J Adv Nurs. 1990; 15: 210-15. http://dx.doi.org/10.1111/j.1365-2648. 1990.tb01804.x

[8] Vanlaere L, Gastmans C. Ethics in nursing education: learning to reflect on care practices. Nursing Ethics. 2007; 14(6): 75866. PMid:17901186 http://dx.doi.org/10.1177/096973300 7082116

[9] Lachman V. Practical use of the Nursing Code of ethics; Part II. MedSurg Nursing. 2009; 18(3): 191-4. PMid:19591369
[10] Nibert A. Teaching Clinical Ethics Using a Case Study: Family Presence During Cardiopulmonary Resuscitation. Crit Care Nurse. 2005; 25(1): 38-44. PMid:15756732

[11] Osingada C, Nalwadda G, Ngabirano T, et al. Nurses' knowledge in ethics and their perceptions regarding continuing ethics education: a cross-sectional survey among nurses at three referral hospitals in Uganda. BMC Res Notes. 2015; 8: 319-24. PMid:26219840 http://dx.doi.org/10.1186/s13104-015-1294-6

[12] Iglesias M, Vallejo R. Nurse attitudes in relation to health care ethics and legal regulations for nursing. Acta Bioethica. 2014; 20(2): 255-64. http://dx.doi.org/10.4067/S1726-569X201 4000200013

[13] Chopra1 M, Bhardwaj N, Mithra P. Current status of knowledge, attitudes and practices towards healthcare ethics among doctors and nurses from northern india - a multicentre study Pravara Med Rev. 2014; 6(2): 4-8.

[14] Aliyu D, Adeleke I, Omoniyi S, et al. Knowledge, attitude and practice of nursing ethics and law among nurses at Federal Medical Centre, Bida. American Journal of Health Research. 2015; 3(1-1): 32-7.

[15] Hariharan S, Jonnalagadda R, Walrond E, et al. Knowledge, attitudes and practice of healthcare ethics and law among doctors and nurses in Barbados. BMC Medical Ethics. 2006; 7: 7. PMid:16764719 http://dx.doi.org/10.1186/1472-6939-7-7

[16] Robichaux C. Developing Ethical Skills: From Sensitivity to Action. Crit Care Nurse. 2012; 32(2): 65-72. PMid:22467614 http: 
//dx.doi.org/10.4037/ccn2012929

[17] Grace P. Nursing ethics. In: Nursing Ethics and Professional Responsibility in Advanced Practice. Sudbury, MA: Jones \& Bartlett; 2009. 33-68.

[18] Weaver K, Morse J, Mitcham C. Ethical sensitivity in professional practice: concept analysis. J Adv Nurs. 2008; 62(5): 60718. PMid:18355227 http://dx.doi .org/10.1111/j.1365-264 8.2008.04625.x

[19] Bebeau M. The defining issues test and the four component model: contributions to professional education. J Moral Educ. 2002; 31(3): 271-95. PMid:15027443 http://dx.doi.org/10.1080/03057 24022000008115

[20] Burkhardt MA, Nathaniel AK. Ethics and Issues in Contemporary Nursing. 2nd ed. Albany, NY: Delmar/Thompson Learning; 2002.

[21] Lachman V. Moral courage: a virtue in need of development? Medsurg Nurs. 2007; 16(2): 131-3. PMid:17547273

[22] Meyer EC, Ritholz MD, Burns JP, et al. Improving the quality of end-of-life care in the intensive care unit: parents' priorities and recommendations. Pediatrics. 2006; 117(3): 649-57. PMid:16510643 http://dx.doi.org/10.1542/peds.2005-0144

[23] Aiken L, Clarke S, Sloane D, et al. Effects of hospital care environment on patient mortality and nurse outcomes. J Nurs Adm. 2009; 39(7-8 suppl): S45-S51.

[24] Rushton C, Penticuff J. A Framework for Analysis of Ethical Dilemmas in Critical Care Nursing. AACN Advanced Critical Care. 2007; 18(3): 323-8. PMid:18019523 http://dx.doi .org/10.1097/01. AACN . 0000284434.83652.d5

[25] Gustafsson G, Eriksson S, Strandberg G, et al. Burnout and perceptions of conscience among health care personnel: a pilot study. Nurs Ethics. 2010; 17(1): 23-8. PMid:20089623 http://dx.doi.org/1 $0.1177 / 0969733009351950$

[26] Robichaux C, Parsons M. An ethical framework for developing and sustaining a healthy workplace. Crit Care Nurs Q. 2009; 32(3): 199207. PMid:19542971 http://dx. doi .org/10.1097/CNQ. 0 b013 e3181ab91ff

[27] American Association of Critical-Care Nurses. Ethics of care. 2015. Available from: http://www . aacn.org/wd/practice/content /ethicmainpage.pcms?menu=practice
[28] American Nurses Association. Code of Ethics for Nurses with Interpretive Statements 2015. Washington: American Nurses Association; 2015. Available from: http://www.nursingworld .org/MainMenuCategories/EthicsStandards/CodeofEthi csforNurses/Code-of-Ethics-For-Nurses.html

[29] Ulrich C, Taylor C, Soeken K, et al. Everyday Ethics: Ethical Issues and Stress in Nursing Practice. J Adv Nurs. 2010; 66(11): 215. PMid:20735502 http://dx.doi.org/10.1111/j.1365-264 8.2010.05425.x

[30] Verpeet E, Dierckx de Casterle' B, van der Arend A, et al. Nurses' views on ethical codes. A focus group study. J Adv Nurs. 2005; 51: 188-95. PMid:15963191 http://dx.doi.org/10.1111/j.1 $365-2648.2005 .03513 . x$

[31] Fry S, Johnstone MJ. Ethics in nursing practice. A guide to ethical decision making. Oxford: Blackwell; 2002.

[32] Grady C, Danis M, Soeken KL, et al. Does ethics education influence the moral action of practicing nurses and social workers? Am J Bioeth. 2008; 8(4): 4-11. PMid:18576241 http://dx.doi.org/1 $0.1080 / 15265160802166017$

[33] Wocial L. An urgent call for ethics education. Am J Bioeth. 2008; 8(4): 21-3. PMid:18576247 http://dx.doi.org/10.1080/152 65160802147041

[34] Jurchak M, Pennington M. Fostering moral agency in new intensive care unit nurses. Crit Care Nurse. 2009; 29(6): 79-80. http: $/ /$ dx.doi.org/10.4037/ccn2009519

[35] Helft PR, Bledsoe PD, Hancock M, et al. Facilitated ethics conversations: a novel program for managing moral distress in bedside nursing staff. JONAS Healthc Law Ethics Regul. 2009; 11(1): $27-$ 33. PMid:19265343 http://dx.doi.org/10.1097/NHL.0b013 e31819a787e

[36] Hsu LL. Blended learning in ethics education: A survey of nursing students. Nursing Ethics. 2011; 18(3): 418-30.

[37] Engward H. Exploring undergraduate student nurses situated experiences of ethics: Centering students through story discussion. Occasional Papers in Education \& Lifelong Learning. 2010; 4(1): 49-60. PMid:21558117 http://dx.doi.org/10.1177/0969733 011398097 